\title{
Assessment and Comparison of Accuracies of Three Differential Global Positioning System (DGPS) Data Processing Software
}

\author{
Bala, M. G. \\ Department of Basic Science \\ College of Agriculture, Gujba, P.M.B. 1104 \\ Damaturu, Yobe State \\ Nigeria \\ Edan J. D \\ Mohammed A. \\ Department of Surveying and Geoinformatics \\ Modibbo Adama University of Technology, P.M.B. 2076 \\ Yola, Adamawa State Nigeria
}

\begin{abstract}
The research investigates the capability and accuracy of three different instruments software used in processing Differential Global Positioning System (DGPS) data. To examine this task, a reference network comprising of 20 control points was established using static mode observations. The data were collected using Promark3 DGPS and were processed using the three different software namely Ashtech Office Suite (AOS), Trimble Business Center (TBC) and Hi-target Geomatics Office (HGO). Statistical analyses did not show any significant difference between the three processing software. The three software were further evaluated and analyzed graphically using Error ellipse. The results indicated that HGO has the least uncertainty of $16.2632 \%$ average value of the axis, but it fails to process one of the points (MG12). TBC software had the second uncertainty average value of the axis of $16.3158 \%$. The third software, AOS yielded $67.4210 \%$ uncertainty average value of the axis. TBC and HGO were therefore revealed to have the same precision, but HGO has limitation in terms of antenna selection. In DGPS surveys, TBC software is therefore recommended for processing data observed by any GPS receiver.
\end{abstract}

Keywords: DGPS, Post Processing, Differential Correction, Relative Precision, Ambiguity and Uncertainty

\subsection{Introduction}

In the earlier days surveying was labour intensive, time consuming and less accurate. The development of Global Positioning System (GPS) technologies have made the acquisition of highly accurate and reliable data possible with reduced physical efforts. These technologies reduced about one half of project cost and save about two third of the project time when compared to the conventional methods (Kumar et al. 2012). With the advancement of technology, surveys have become faster and milestone successes have been achieved. Some of the most important ones have come in the form of software which can greatly improve the speed of delivery and the GPSs ability to overcome the problem of intervisibility (Ansah, 2006).

As with traditional geodetic network adjustment, data processing for precise GPS static positioning is invariably performed using the least-squares method. To employ the least-squares method, both the functional and stochastic models of the GPS measurements need to be defined. The functional model, also called the mathematical model, describes the mathematical relationships between the GPS measurements and the unknown parameters, such as the ambiguity terms and the baseline components. The stochastic model describes the statistical properties of the measurements, which are mainly defined by an appropriate covariance matrix. In order to ensure high accuracy, both the functional model and the stochastic models must be correctly defined. If the function model is adequate, the residuals obtained from the least-squares solution is randomly distributed. Over the last two decades the functional models for GPS carrier phases have been investigated in considerable detail, and are well documented in the literature, (Satirapod, 2002). 
Accuracy is the degree of conformity with a standard or a measure of closeness to a true value. It relates to the quality of the result obtained when compared to the standard. Since a GPS receiver calculates its position once every second and each measurement is subjected to introduce errors, the position is slightly different from the previous one, even if the receiver is static at one location.

Real-time differential correction for Real-time DGPS has had a very positive effect on navigation and verification of spatial data. But there are places in the world that do not have reliable real-time DGPS services, and many applications need better accuracy than is achievable from current real-time correction methods. Differential correction is a method of removing the errors, both man-made and natural that affect GPS measurements. Correction of GPS coordinates can be accomplished at a later time (post processing) or while the roving GPS receiver is in use. Depending on the technique used, post processed differential correction can deliver GPS data accurate to few maters in moving applications and to a few centimetre in stationary situations, these levels of accuracy are now easier than ever to achieve (Trimble, 2004).

\subsection{Research Problem}

In recent times, there is a proliferation in the use of different software technology in the field of Surveying and Geoinformatics. Numerous manufacturers keep on developing various types of GPS technologies such as Promark3, Topcon and Leica for different surveying purposes. These instruments' have their respective processing software which often pose problems to surveyors and engineers when processing field data and adjusting results. The problems vary from incompatibility to inaccuracy in obtaining data. These are essential issues in the field of surveying and Geoinformatics with regards to technology application but they are neglected by several researchers and studies. In order to address these problems, this research seeks to investigate the capability of different instruments' software to process data observed using any GPS receiver, and to identify the model that will make different GPS receivers to work with one another's software and find the most accurate among these software when it comes to data processing and adjusting results.

\subsection{Study Area}

To obtain the data used in this research, a DGPS survey was conducted at Modibbo Adama University of Technology (MAUTECH) Yola main campus. This area of study is located along Yola-Mubi road in Girei Local Government Area of Adamawa, Nigeria. As shown in Figure 1, the study area extends from $12^{\circ} 28^{\prime} 02^{\prime \prime} \mathrm{E}$ to $12^{\circ}$ $30^{\prime} 32^{\prime \prime} \mathrm{E}$ in longitude and $9^{\circ} 19^{\prime} 48^{\prime \prime} \mathrm{N}$ to $9^{\circ} 24^{\prime} 18^{\prime \prime} \mathrm{N}$ in latitude, covering an area of $4317.579 \mathrm{Ha}$ (Mohammed et. al. 2017).

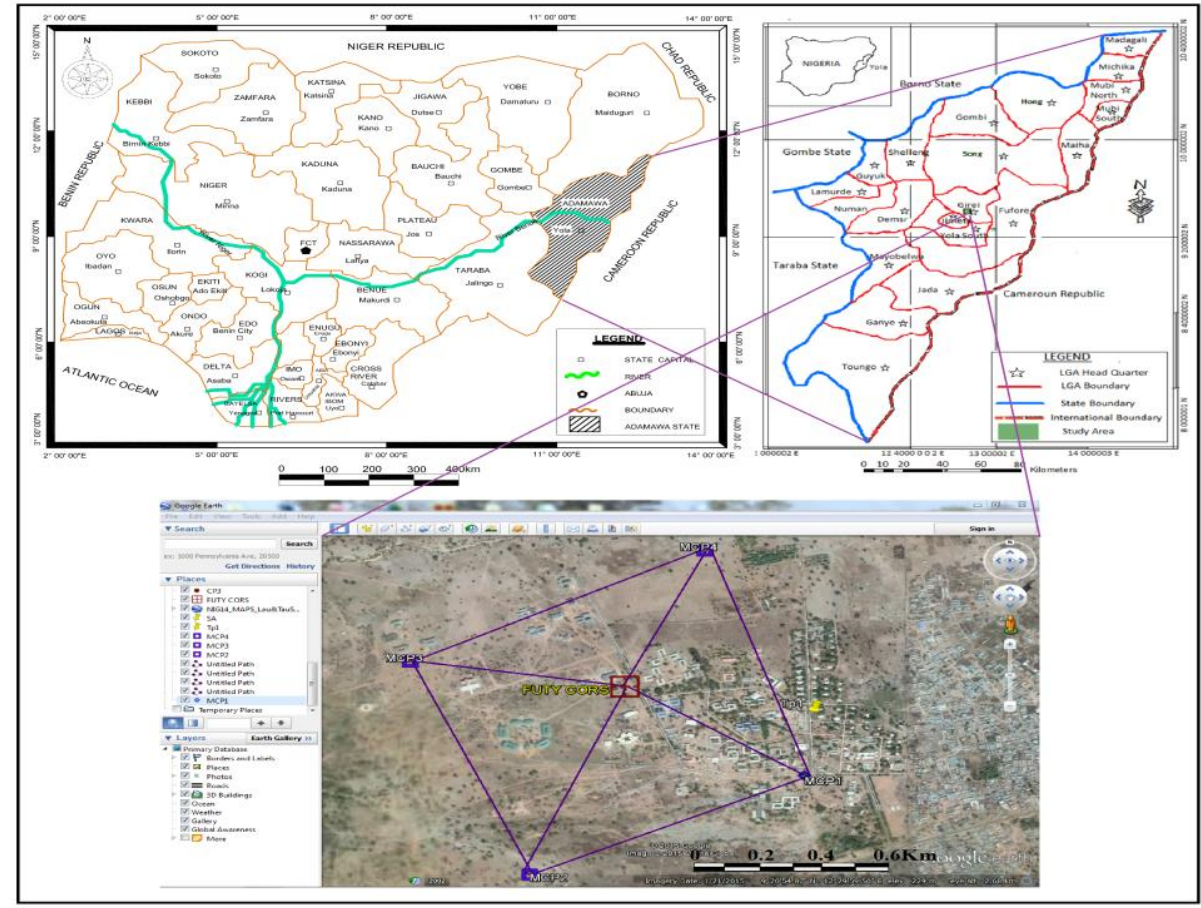

Figure 1: Location of the Study Area 


\subsection{Methods/Materials}

Prior to field data acquisition, the static survey was first planned using GPS mission planning to increase chances of success in the DGPS survey. The network design and observation plan which are the two primary areas of static survey planning were duly adhered to in the GPS mission planning (satellite prediction analysis). Upon the completion of the network design and planning mission, the intent of the data collection was achieved. The procedure for data acquisition and processing, results and analysis of the results are therefore described in the following paragraphs

\subsection{Data Acquisition}

The study involved the use of ProMark 3 GPS on differential mode to acquire field data. 20 stations were marked and monumented on ground in accordance to specific regulations within the study area during reconnaissance survey. 30 minutes Post Processing Static (PPS) rover observations were carried out on all the established points at a sampling rate of 2 seconds. The acquired data were later downloaded into a computer from the receivers to commence processing.

\subsection{Data Processing}

Data processing algorithm for software employed in this research include Ashtech Office Suite (AOS), Trimble Business Center (TBC) and Hi-target Geomatics Office (HGO) which vary slightly depending on the manufacturers' instruction and guideline; but few steps are common to all of them. The coordinates of 20 control points were processed and adjusted with AOS and TBC. However, HGO failed to process and adjust one of the 20 control points (MG12). This may be due to the fact that there is no provision for selecting antenna type used during the field operation.

\subsection{Results Presentation}

The results for most probable values (MPVs) of coordinates computed are presented as shown in Tables 1 to 3 .

Table 1: Processed UTM Coordinates (WGS 84) with AOS GNSS Solutions Software

\begin{tabular}{lllll}
\hline S/No & Name & Easting $(\mathrm{m})$ & Northing $(\mathrm{m})$ & $\begin{array}{l}\text { Ellipsoidal } \\
\text { height }(\mathrm{m})\end{array}$ \\
\hline 1 & MG10 & 223902.5400 & 1034279.2440 & 222.4150 \\
2 & MG11 & 223805.4820 & 1034746.1720 & 215.7700 \\
3 & MG12 & 224809.8520 & 1035048.1030 & 223.6360 \\
4 & MG13 & 224701.9880 & 1034641.4920 & 230.4810 \\
5 & MG14 & 224610.6350 & 1034285.3050 & 232.6700 \\
6 & MG15 & 225072.5650 & 1034303.7080 & 239.3470 \\
7 & MG16 & 225431.2100 & 1034643.6940 & 235.6200 \\
8 & MG17 & 225780.9400 & 1034544.9560 & 239.6270 \\
9 & PC03 & 224314.3840 & 1034923.5000 & 220.1900 \\
10 & CM03 & 224314.4570 & 1034923.4030 & 218.1140 \\
11 & MG01 & 226176.4390 & 1033767.1870 & 247.1240 \\
12 & MG02 & 225698.8590 & 1033550.3960 & 243.5610 \\
13 & MG03 & 225252.6520 & 1033404.1510 & 235.6930 \\
14 & MG04 & 224796.3250 & 1033203.8730 & 236.1880 \\
15 & MG05 & 224296.3570 & 1032378.8600 & 247.1220 \\
16 & MG06 & 223944.6680 & 1032958.0050 & 232.8620 \\
17 & MG07 & 224262.8430 & 1033235.9330 & 231.7450 \\
18 & MG08 & 224098.3180 & 1033323.9450 & 227.9940 \\
19 & MG09 & 224635.4860 & 1033514.8220 & 228.7820 \\
20 & UMY6 & 224249.1000 & 1033765.3480 & 222.0800 \\
\hline
\end{tabular}


Table 2: Processed UTM Coordinates (WGS 84) with TBC Software

\begin{tabular}{lllll}
\hline S/No & Name & Easting $(\mathrm{m})$ & Northing $(\mathrm{m})$ & $\begin{array}{l}\text { Ellipsoidal } \\
\text { height }(\mathrm{m})\end{array}$ \\
\hline 1 & MG10 & 223903.5780 & 1034278.5340 & 209.1940 \\
2 & MG11 & 223806.7970 & 1034744.2590 & 196.2060 \\
3 & MG12 & 224811.2720 & 1035048.0550 & 203.8820 \\
4 & MG13 & 224699.7530 & 1034641.1920 & 223.2300 \\
5 & MG14 & 224610.0180 & 1034283.8240 & 219.9910 \\
6 & MG15 & 225077.1910 & 1034302.5240 & 218.2360 \\
7 & MG16 & 225431.6930 & 1034643.4350 & 219.5510 \\
8 & MG17 & 225779.3130 & 1034543.0820 & 216.3410 \\
9 & PC03 & 224314.7770 & 1034922.0660 & 202.7860 \\
10 & CM03 & 224313.0880 & 1034921.4290 & 207.7090 \\
11 & MG01 & 226178.9480 & 1033766.6870 & 233.7830 \\
12 & MG02 & 225701.2960 & 1033549.1190 & 225.6630 \\
13 & MG03 & 225253.8790 & 1033403.9120 & 216.9870 \\
14 & MG04 & 224796.8790 & 1033203.1960 & 221.9060 \\
15 & MG05 & 224298.0400 & 1032381.1250 & 235.3560 \\
16 & MG06 & 223945.0290 & 1032956.3570 & 220.8020 \\
17 & MG07 & 224264.2360 & 1033234.1570 & 218.9330 \\
18 & MG08 & 224098.0250 & 1033322.5920 & 214.7450 \\
19 & MG09 & 224635.2710 & 1033514.0230 & 216.4680 \\
20 & UMY6 & 224254.1140 & 1033765.7440 & 212.9670 \\
\hline
\end{tabular}

Table 3: Processed UTM Coordinates (WGS 84) with HGO Software

\begin{tabular}{lllll}
\hline S/No & Name & Easting $(\mathrm{m})$ & Northing $(\mathrm{m})$ & $\begin{array}{l}\text { Ellipsoidal } \\
\text { height }(\mathrm{m})\end{array}$ \\
\hline 1 & MG10 & 223903.5777 & 1034278.5350 & 225.9999 \\
2 & MG11 & 223806.7970 & 1034744.2590 & 213.0074 \\
3 & MG12 & Fail & Fail & Fail \\
4 & MG13 & 224699.7535 & 1034641.1920 & 240.0218 \\
5 & MG14 & 224610.0178 & 1034283.8240 & 236.7882 \\
6 & MG15 & 225077.1914 & 1034302.5240 & 235.0266 \\
7 & MG16 & 225431.6934 & 1034643.4350 & 236.3329 \\
8 & MG17 & 225779.3133 & 1034543.0820 & 233.1201 \\
9 & PC03 & 224314.7766 & 1034922.0660 & 219.5783 \\
10 & CM03 & 224313.0879 & 1034921.4290 & 224.5017 \\
11 & MG01 & 226178.9478 & 1033766.6870 & 250.5669 \\
12 & MG02 & 225701.2956 & 1033549.1190 & 242.4551 \\
13 & MG03 & 225253.8793 & 1033403.9120 & 233.7871 \\
14 & MG04 & 224796.8792 & 1033203.1960 & 238.7141 \\
15 & MG05 & 224298.0396 & 1032381.1250 & 252.1812 \\
16 & MG06 & 223945.0286 & 1032956.3580 & 237.6240 \\
17 & MG07 & 224264.2363 & 1033234.1570 & 235.7477 \\
18 & MG08 & 224098.0252 & 1033322.5920 & 231.5599 \\
19 & MG09 & 224635.2712 & 1033514.0230 & 233.2742 \\
20 & UMY6 & 224254.1140 & 1033765.7440 & 229.7747 \\
\hline
\end{tabular}

\subsection{Analysis of the Results}

Two main statistical distributions were used: Chi-square $\left(\chi^{2}\right)$ and the $\mathrm{t}$ or student-t distributions. The $\chi^{2}$ distribution was used to test the sample variance to determine whether it was in agreement with the population variance. A confidence region was established for the sample variance. The actual location of the sample variance was based on some specific percentage probability. 
The sample set variances and the degrees of freedom for the particular problem and to test the variance, a confidence region was created. Harvey (1994) gave the test statistics as given in equations (1) and (2).

$$
\begin{array}{r}
\chi^{2}=\frac{(n-1) S^{2}}{\sigma^{2}} \\
\frac{d f S^{2}}{\chi_{(\alpha / 2)}^{2}}<\sigma^{2}<\frac{d f S^{2}}{\chi_{(1-\alpha / 2)}^{2}}
\end{array}
$$

where $\mathrm{df}$ is the degrees of freedom and $(1-\alpha)$ is the confidence interval and $\mathrm{n}$ the number of observations.

The results of the Analysis of Variance (ANOVA) shown in Table 4 decomposed the variance of the data into two components namely: a between-group component and a within-group component. The F-ratio, which in this case equals 0.000352011 , is a ratio of the between-group estimate to the within-group estimate. Since the P-value of the F-test is greater than or equal to 0.05 , there is no statistical significant difference between the means of the 3 variables at the $95.0 \%$ confidence level.

Table 4: Analysis of Variance of the three Software (ANOVA)

\begin{tabular}{llllll}
\hline Source & $\begin{array}{l}\text { Sum } \\
\text { Squares }\end{array}$ & of & Dean Square & F-Ratio & P-Value \\
\hline Between groups & 323.583 & 2 & 161.791 & 0.00 & 0.9996 \\
Within groups & 25738700 & 56 & 459620.0 & & \\
Total (Corr.) & 25739000 & 58 & & & \\
\hline
\end{tabular}

The table of multiple ranges in Table 5 applied a multiple comparison procedure and determined the means that were significantly different from one another. The bottom half of the output showed the estimated difference between each pair of means. There were no statistical significant differences between any pair of means at the 95.0\% confidence level. In the top 3 rows of the same Table 5, one homogenous group was identified by a column of Xs. Within each column, the levels containing Xs form a group of means within which there were no statistical significant differences. The method currently being used to classify among the means is Fisher's least significant difference (LSD) procedure. With this method, there is a 5.0\% risk of calling each pair of means significantly different when the actual difference equals 0 .

\begin{tabular}{|c|c|c|c|c|}
\hline Software & & Count & Mean & Homogeneous groups \\
\hline HGO & & 19 & 224703.0 & $X$ \\
\hline AOS & & 20 & 224708.0 & $\mathrm{X}$ \\
\hline TBC & & 20 & 224709.0 & $\mathrm{X}$ \\
\hline Contrast & & Difference & +/- Limits & \\
\hline AOS & - HGO & 4.49577 & 435.085 & \\
\hline $\mathrm{AOS}$ & $-\mathrm{TBC}$ & -0.90485 & 429.47 & \\
\hline
\end{tabular}

Table 5: Multiple Range Tests (Orthogonal contracts) of the three software

\subsection{Coordinate Standard Deviations and Relative Error Ellipse}

In error ellipse, the long semi-axis depicts the direction of greatest uncertainty while the short semi-axes show that of the smallest uncertainty (Vermeer, 2008). In trying to compare the level of graphical uncertainty of the three software, the percentage of sigma values were computed and resulted to $67.4210 \%, 16.3158 \%$ and $16.2632 \%$ of AOS, TBC and HGO respectively as shown in Figures 7 and 8. Error ellipses were also drawn on common origin (Figure 2) and it reveals that there were no significant differences between the two software: AOS, TBC and HGO as shown in Figure 3, but it showed great uncertainty of AOS compare to TBC and HGO. On MG12 both AOS and TBC resulted to 50\% each of their sigma values as shown in Figure 4 and on the same figure, it also shows that TBC (Red error ellipse) and HGO (Green error ellipse) have the same precision, That is the reason why red error ellipses concealed out under the green error ellipse. 
Table 6: Computed Parameters of Relative Error Ellipses

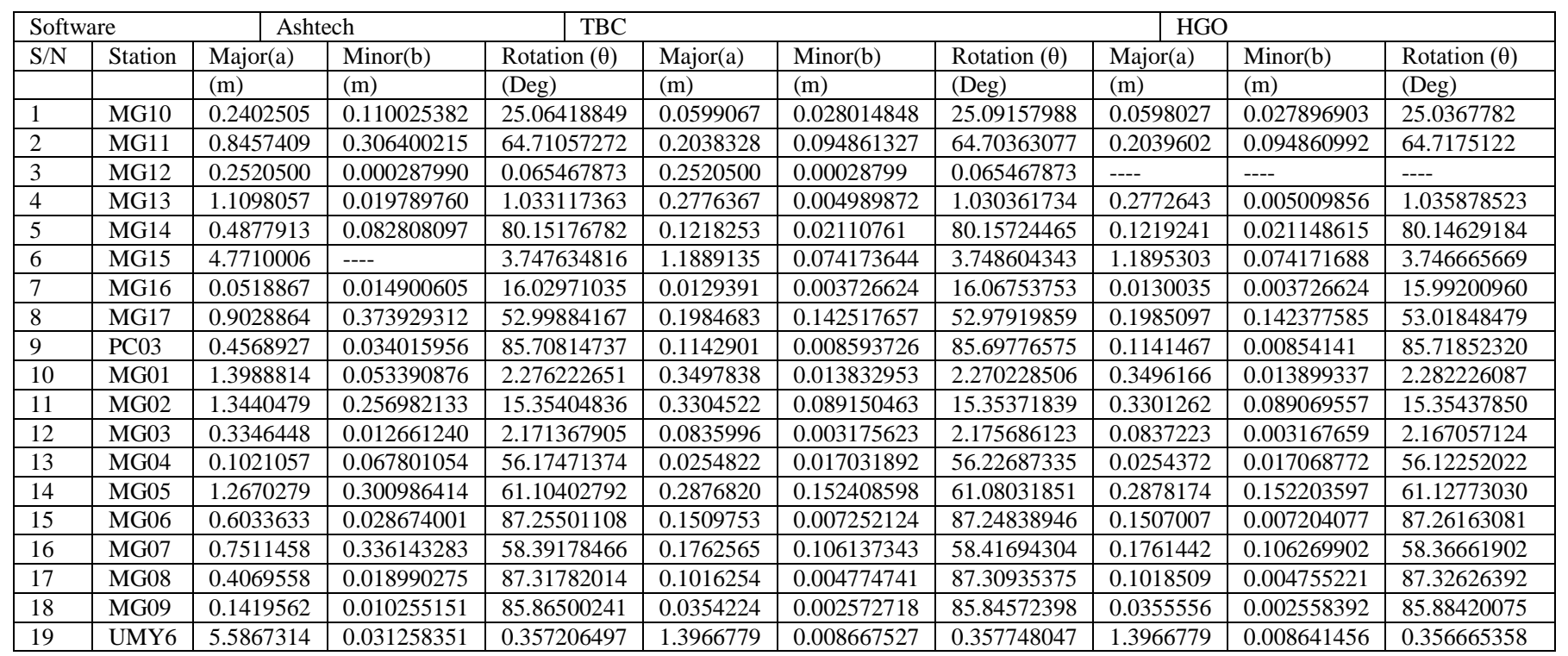

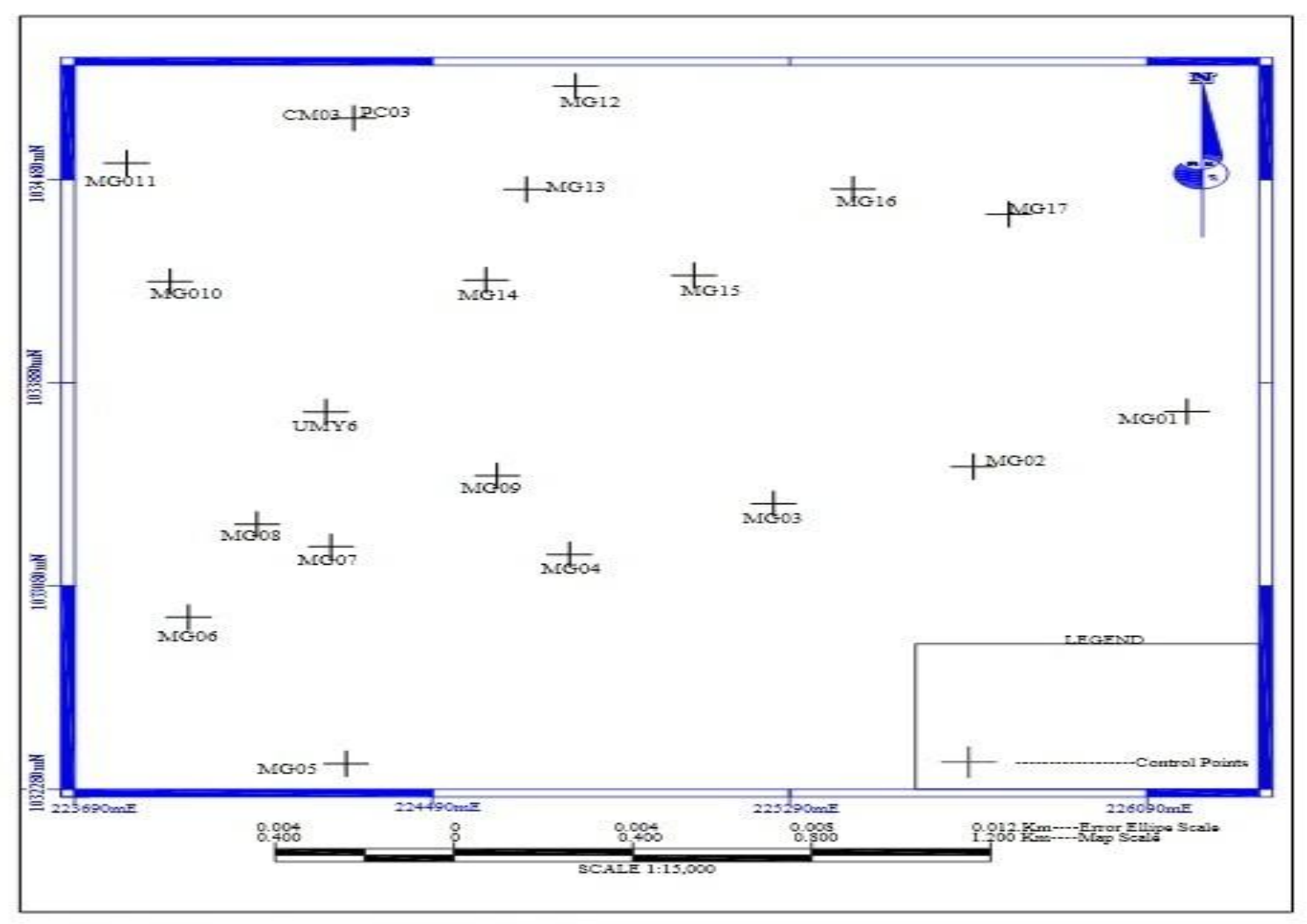

Figure 2: Plan Showing the Established Control Points 


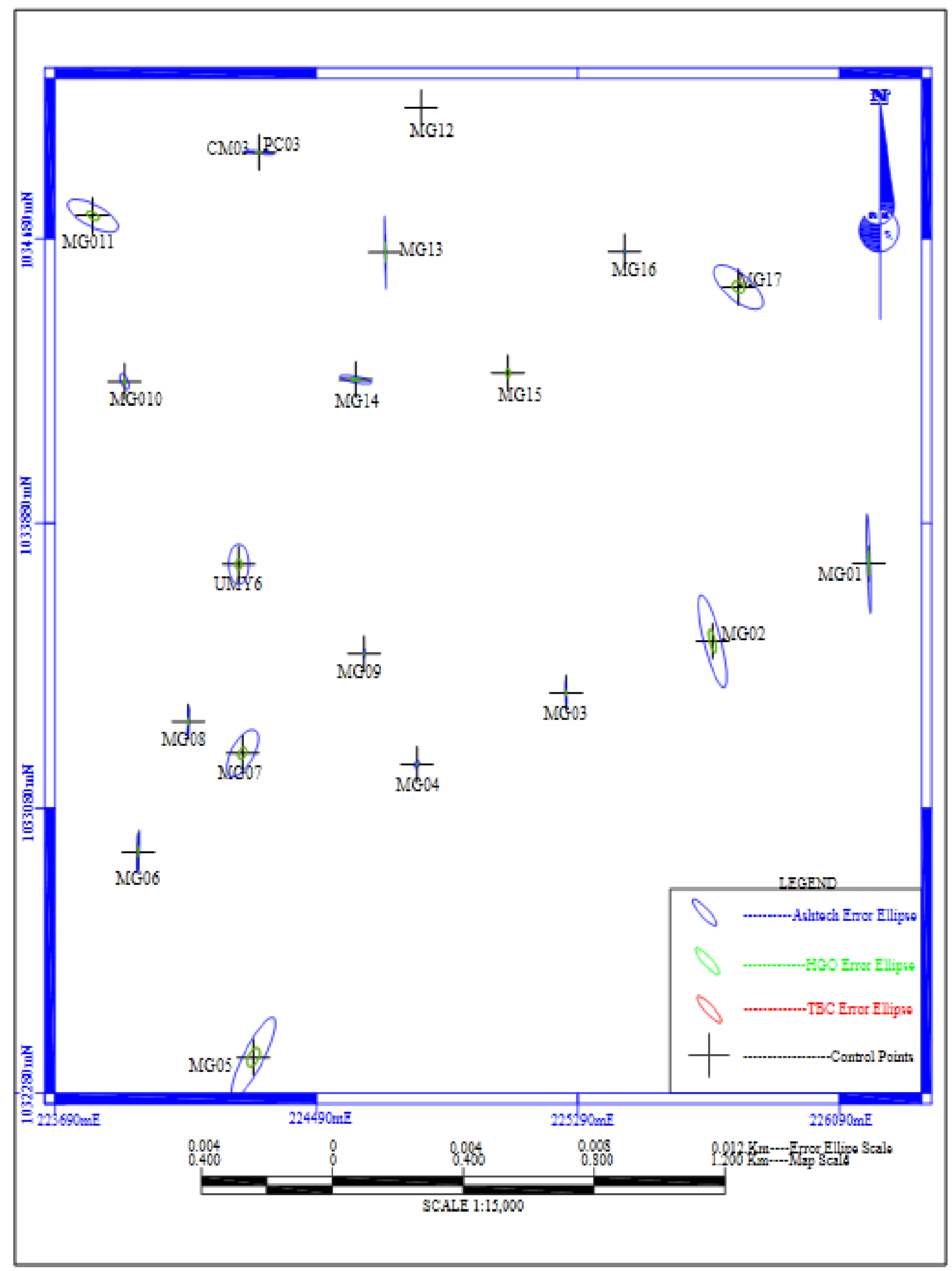

Figure 3: Plan Showing the Control Points, AOS, HGO and TBC 


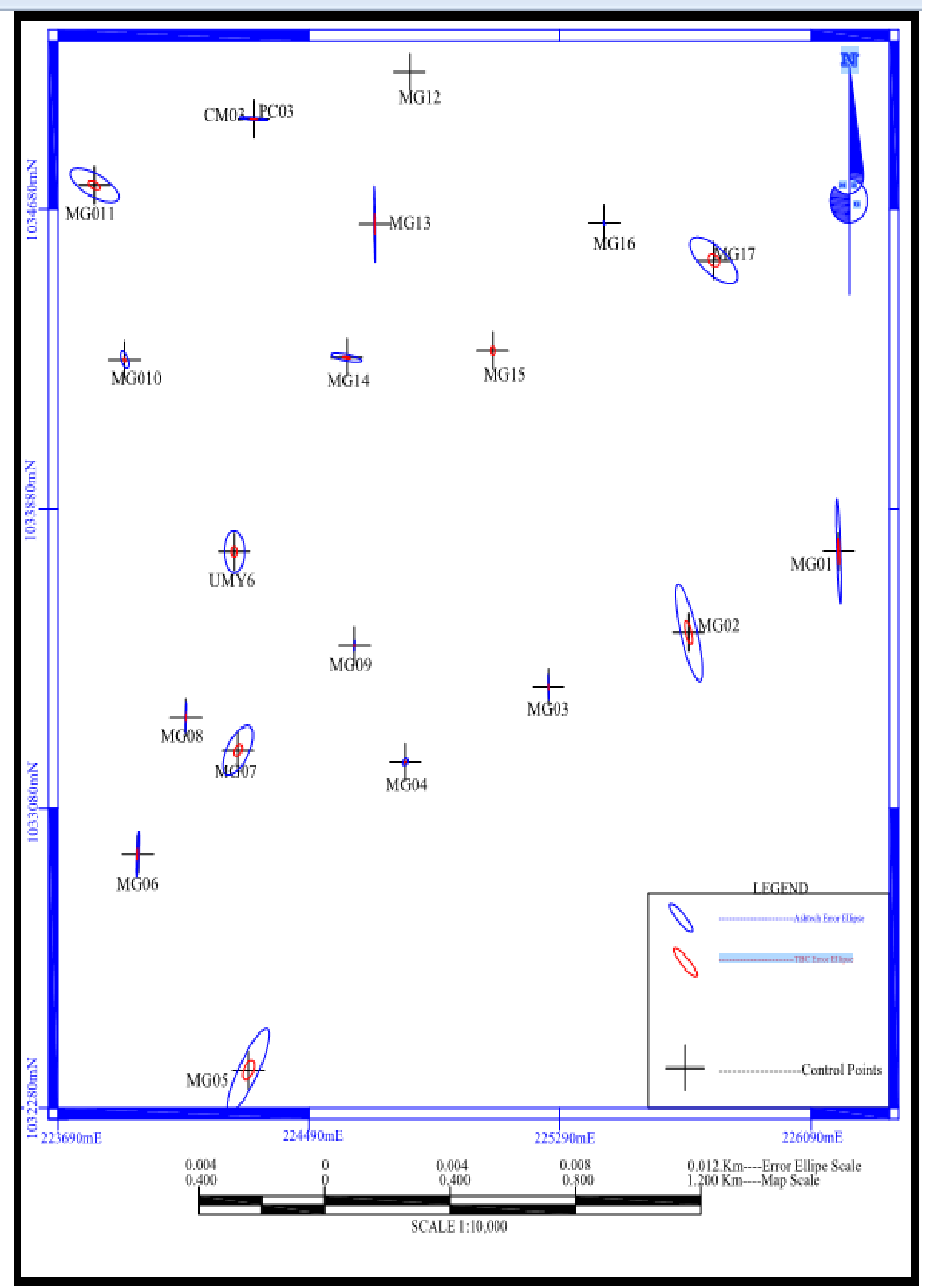

Figure 4: Plan Showing the Control Points, AOS and TBC 


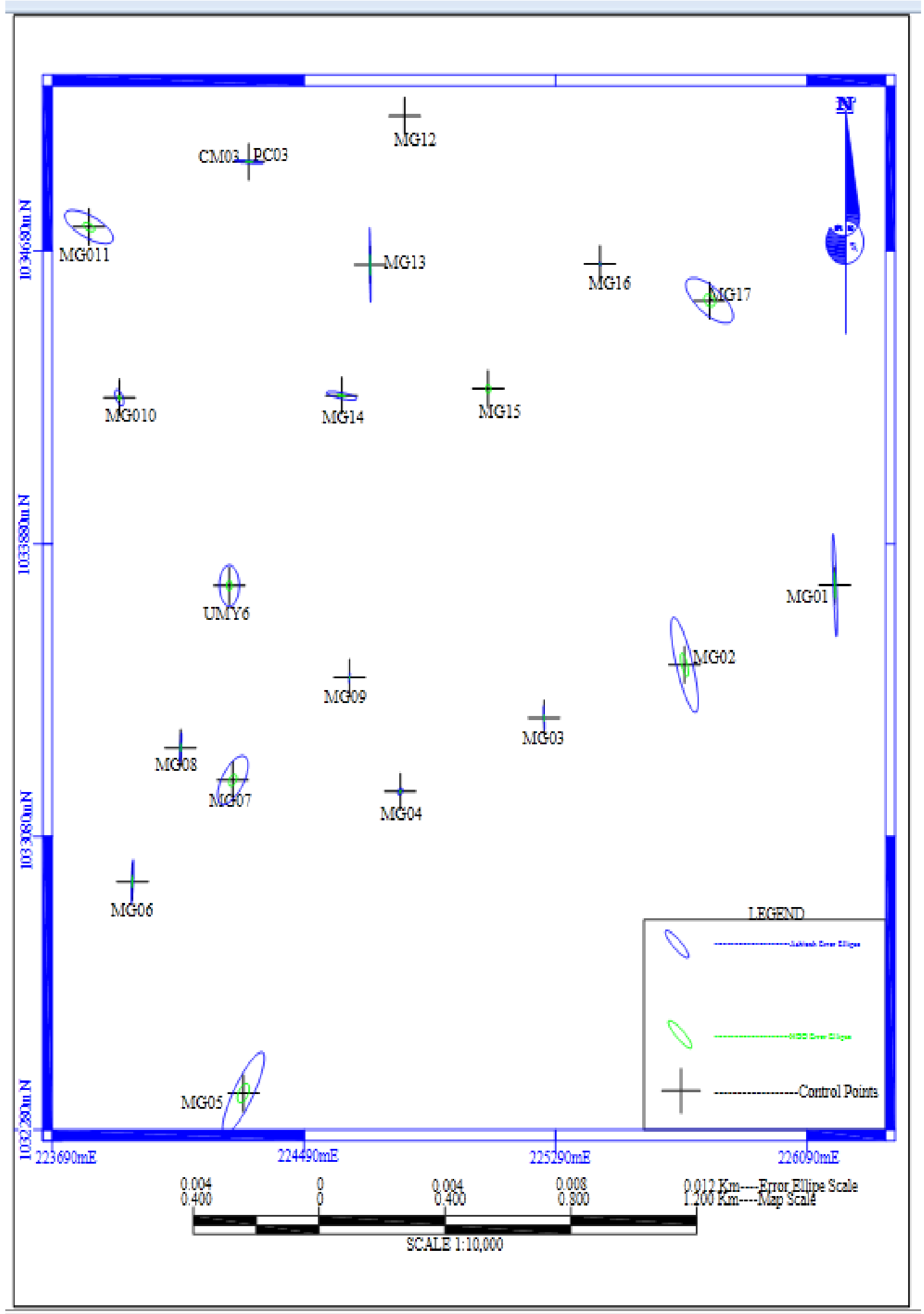

Figure 5 Plan showing the control points, Ashtech and HGO 


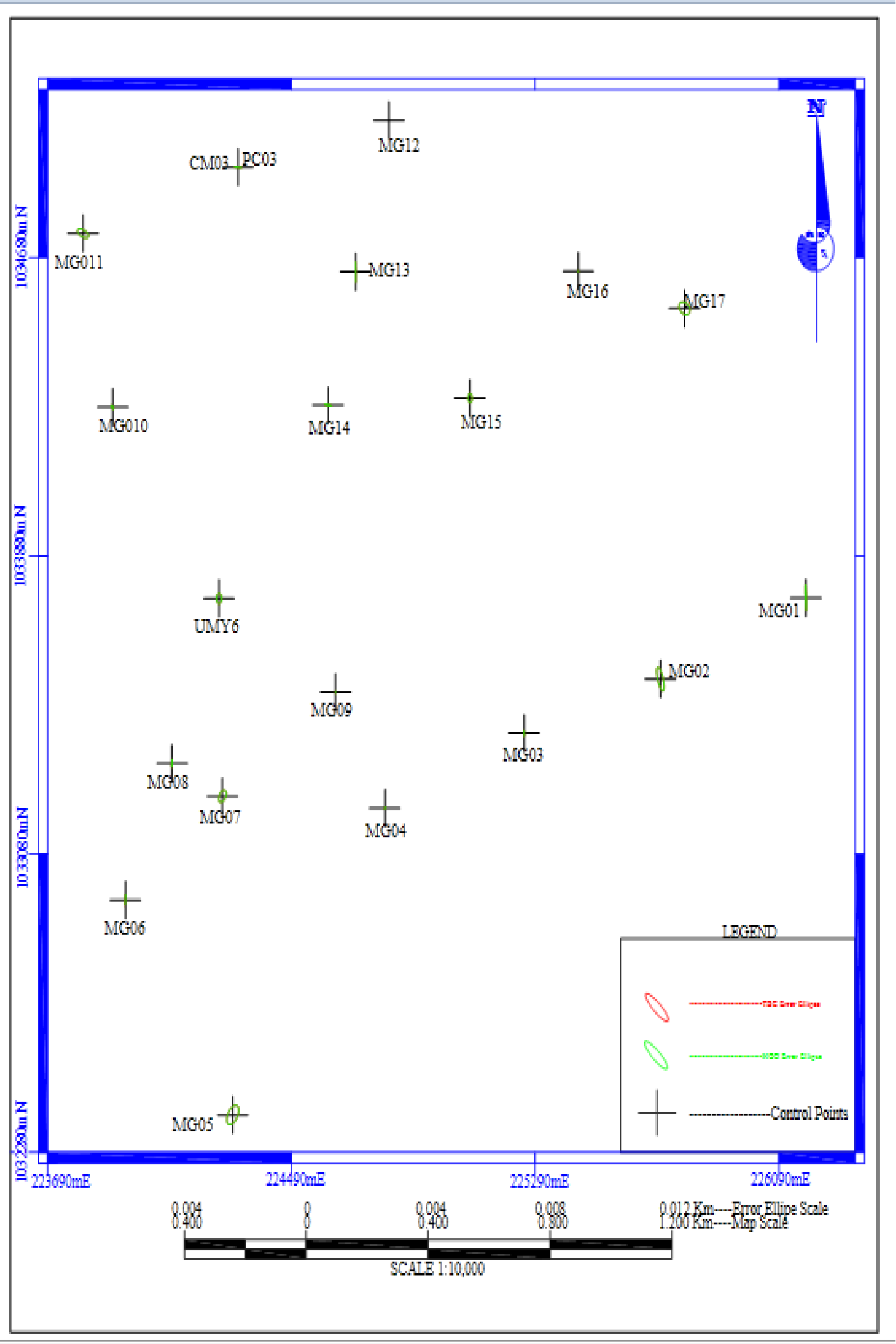

Figure 6: Plan Showing the Control Points, TBC and HGO 


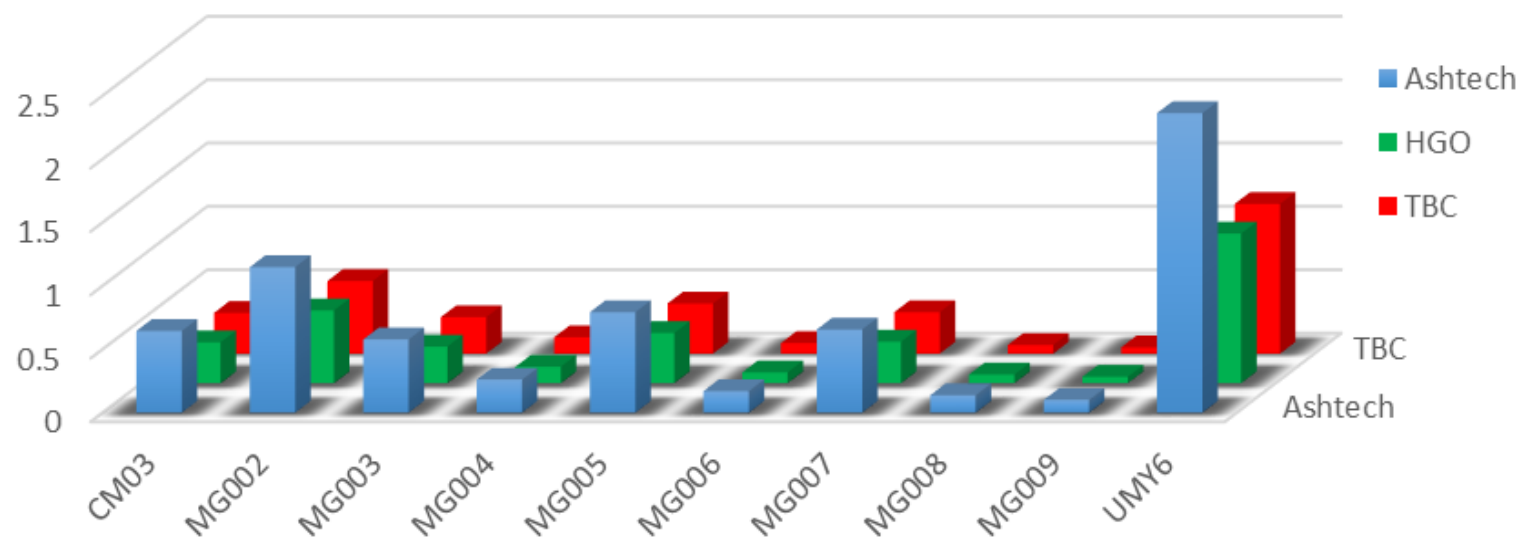

Figure 7: Comparison of Standard Deviation of the three Software on day-1

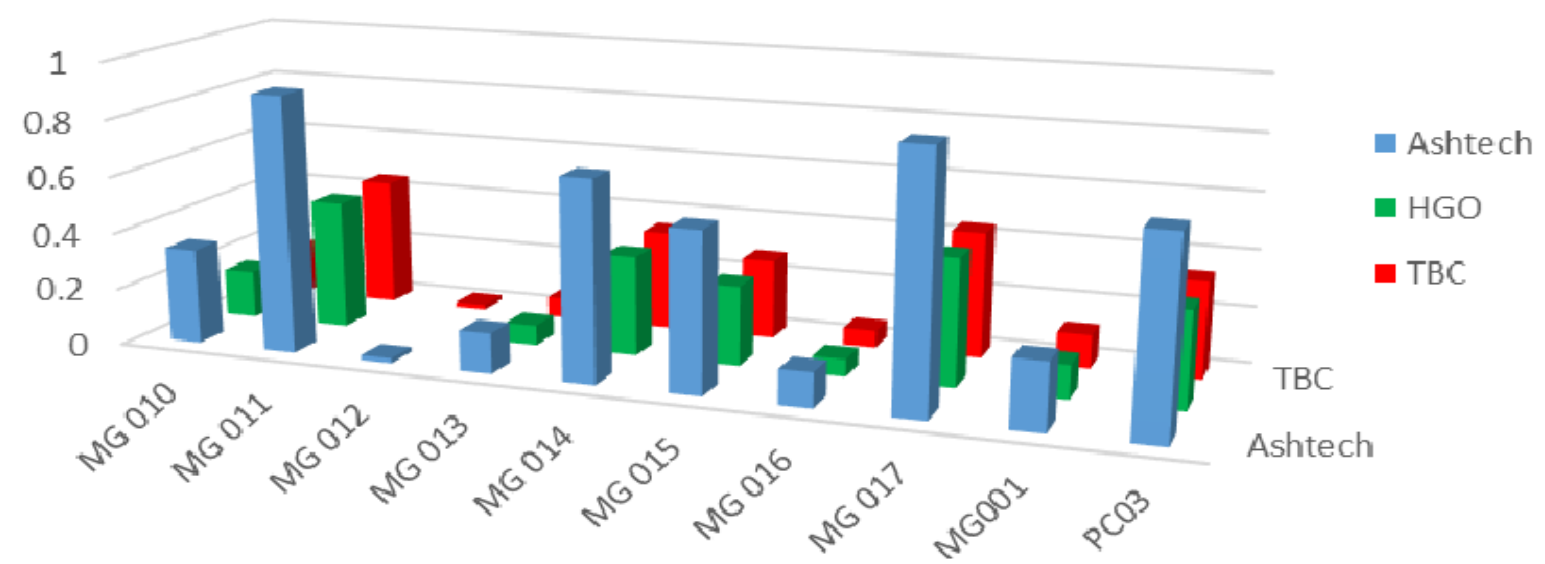

Figure 8: Comparison of Standard Deviation of the three Software on day-2

\subsection{Research Findings}

Based on the results of this research, the research findings are listed as follows:

i. GPS data can be successfully processed using any of the three GPS processing software.

ii. Results can be obtained near pinpoint accuracy using any of the three GPS processing software irrespective of manufactures recommendation.

iii. Processing steps are similar for all the three software including creating new project, importing data, manipulation, processing and exporting of information produced to Microsoft Excel.

iv. Data in RINX-File format is readable for all the three GPS processing software.

v. The Trimble Business Center software (TBC) is secured by the manufacturer. Therefore data can only be processed with the use of dongle key.

vi. TBC have provision for selecting antenna type like Magellan.

vii. HGO failed to process MG12 because it has no capability of selecting antenna type.

\subsection{Summary}

The research tried to assess the relative precision of three different data processing software namely, Ashtech Office Suite (AOS), Trimble Business Centre (TBC) and Hi-Target Geomatics Office (HGO). Promark3 Differential Global Positioning System was used and 20 points were occupied (30mins) using static mode observation technique. The results obtained from the three software were analysed and graphically examined using error ellipse. It was revealed that TBC and HGO have the same relative precision. The reliability of the result was studied by means of statistical analysis termed Analysis of Variance (ANOVA) and Multiple Range Test (Orthogonal Contrast). The results did not show any significant difference between the three GPS processing software. 


\subsection{Conclusion/Recommendation}

This study was to test the capability of different software to process DGPS raw data observed using any kind of DGPS receiver, but few mind to carry out rigorous computation to check the precision of the results obtained. Based on the statistical analysis, it was revealed that there is no significant difference between the three processing software. The research showed consistency in the result obtained using TBC and HGO, which have same precision. The two software can be used for processing data observed by any Global Positioning System (GPS) receiver. However, it was indicated that HGO has limitation in terms of antenna selection. Hence, TBC is most recommended.

\section{References}

Ansah, M.O. (2006). Understanding GPS Processing and Results. Shaping the Change XXIII FIG Congress Munich, Germany, Ghana.

Harvey B.R. (1994). Practical least squares and statistics for surveyors (Monograph 13). School of Surveying and Spatial Information Systems, University of New South Wales. 319 pp.

Kumar, P., Chaudhary, K.S., Shukla, G. and Kumar, S (2012). Assessment of Positional Accuracy of DGPS: International Journal of Advances in Earth Sciences, Volume 2, Issue 1,1-7. India.

Mohammed, A., Fajemirokun, F. A., Benjamin, J. B. (2017). Integration of Continuously Operating Reference Stations and Differential Global Positioning System in Second Order Control Establishment. NED University Journal of Research - Applied Sciences, Vol XIV, No. 4, pp-81-92

Satirapod, C. (2002). Improving the GPS Data Processing Algorithm for Precise Static Relative Positioning. Unpublished Doctoral thesis, the University of New South Wales Sydney NSW 2052, Australia.

Trimble (2004). Trimble Navigation Limited Manual. [Computer software and Manual]. Retrieved March 05, 2016

Vermeer, M. (2008). Covariance analysis for geodesy and geophysics. Lecture notes, NKG Summer School, Nesjavellir, Iceland, 25-28 Aug. Landmaelingar Islands, URL: http://www.lmi.is/Files/Skra_0029262.pdf. Accessed date: 2nd February, 2016. 